Este artículo resume un estudio descriptivo sobre el modelo de lengua de la audiodescripción (AD). Ante la inexistencia de estudios similares, como marco analítico del registro propio de la AD se parte del modelo de lengua de oralidad prefabricada en textos de ficción audiovisuales para producciones propias (Baños, 2009). Su aplicación en el guion audiodescrito del largometraje Ocho apellidos vascos permite realizar un análisis lingüístico de los niveles fonético-prosódico, morfológico, léxico y sintáctico. Tras su caracterización, se comparan los resultados tanto con el modelo de lengua de oralidad prefabricada de producciones propias como con el de la lengua del doblaje (dubbese, Chaume, 2004) para determinar a cuál de los dos se asemeja más la lengua de la $A D$ como texto audiovisual de oralidad prefabricada.

PALABRAS CLAVE: audiodescripción, dubbese, guion audiodescrito, modelo de lengua, oralidad prefabricada, accesibilidad.

\title{
La lengua de la
} audiodescripción: análisis del guion audiodescrito de Ocho apellidos vascos

The Language of Audio description: Analysis of the Spanish Audio description Script of Ocho Apellidos Vascos (Spanish Affair).

This article is taken from a descriptive study of the language model of audio description (AD) in Spanish. In the absence of similar studies, I have used the prefabricated orality language model in audiovisual fiction texts for Spanish productions (Baños, 2009) as an analytical framework. Its application in the audio description script of the film Ocho apellidos vascos

ANA VILLOSLADA (Spanish Affair) allows us to perform an analysis of the phonetic-prosodic, University of Exeter morphological, lexical and syntactic language levels. After the characterization of these levels for the $A D$, I have compared the results with both the prefabricated orality of Spanish productions and the dubbese to determine to which of the two the $A D$ language is the closest as a prefabricated orality audiovisual text.

KEY WORDS: audio description, dubbese, audio description script, language model, prefabricated orality, accessibility. 


\section{INTRODUCCIÓN}

En calidad de servicio de accesibilidad, la audiodescripción (en adelante, $\mathrm{AD}$ ) viene a satisfacer el derecho de la población ciega y con discapacidad visual al acceso al ocio y a la información. En los años 70 se realizó la primera tentativa de audiodescripción, consistente en añadir al soporte audiovisual una pista de audio donde iba grabada una voz que describía la imagen, utilizando los espacios sin diálogos en la banda sonora original, proyectó que culminó con creación del sistema AUDESC por parte de la ONCE para impulsar la audiodescripción de obras audiovisuales (Arcos Urrutia, 20I2).

$\mathrm{Su}$ mayor difusión comienza con labores de concienciación por parte de la UE a sus Estados miembros y la implantación de medidas de ocio accesible, como el número de horas de audiodescripción en televisión. Desde entonces, se han sucedido diversas leyes y planes para establecer el sistema de audiodescripción en nuestro país. Cabe destacar la LIONDAU (ley $5_{1} / 2003$ de Igualdad de Oportunidades, No Discriminación y Accesibilidad Universal de las Personas con Discapacidad) y la Ley General Audiovisual (вое, 20Io) que establecía los porcentajes para una implantación progresiva, entre 2010 y 2013 , de servicios de accesibilidad en los canales públicos (BOE, 2OIO: 39):

\begin{tabular}{lllll} 
Servicio* $^{*}$ & 20I0 & 20II & 2012 & 20I3 \\
\hline Subtitulación & $25 \%$ & $50 \%$ & $70 \%$ & $90 \%$ \\
\hline $\begin{array}{l}\text { Horas lengua } \\
\text { signos }\end{array}$ & I & 3 & 7 & I0 \\
\hline $\begin{array}{l}\text { Horas } \\
\text { audiodescripción }\end{array}$ & I & 3 & 7 & 10 \\
\hline
\end{tabular}

\footnotetext{
Evolución de las horas de lenguas de signos y de
audiodescripción en TV de 2010 a 2013.

Evolución de las horas de lenguas de signos y de
audiodescripción en TV de 2010 a 2013.
}

Sin embargo, según el informe titulado Seguimiento del subtitulado y la audiodescripción en la TDT (20I4), elaborado por el CESyA (Centro Español de Subtitulado y Audiodescripción) en colaboración con el CERMI (Comité Español de Representantes de Personas con Discapacidad), la realidad no ha sido $\tan$ halagüeña:

Los servicios de audiodescripción han aumentado desde las 27 horas en $201 \mathrm{I}$ a las I20 del 20I4. Sin embargo, no se cumple con la obligación legal de audiodescribir to horas semanales en los canales públicos y 2 horas semanales en los canales comerciales [...]. Respecto a la audiodescripción, la satisfacción de los usuarios también mejora respecto a la encuesta de 2010 , pero todavía se encuentra en niveles muy bajos. Por otro lado, un $60 \%$ de los encuestados indican que no usan el servicio de audiodescripción, a pesar de necesitarlo (Seguimiento del subtitulado y la audiodescripción en la TDT, 2014: 12).

Los círculos académicos comenzaron a interesarse en la $\mathrm{AD}$ como proceso de traducción intersemiótica a partir de los años 90 (Ramos, 2013: 17), siendo España uno de los países líderes en investigación desde el sector universitario y contando con universidades de referencia como la Universitat Autònoma de Barcelona (Matamala, 2005; Orero, 2007), la Universidad de Granada (Jiménez Hurtado, 2007) o la Universitat Jaume I (Chaume, 200I, 2004; Díaz Cintas, 2007). La AD se estudia principalmente bien desde un enfoque lingüístico-textual, bien desde un enfoque cinematográfico, y mediante metodologías de corpus y estudios de recepción con eye-tracking para dar cuenta del proceso de confección y recepción del producto, describir el guion audiodescrito y entender este fenómeno desde la perspectiva de sus usuarios (Chaume, 200I, 2004, 2012).

El presente artículo muestra los resultados de 
un trabajo de investigación en el que se realizó un estudio descriptivo del lenguaje de la AD en español en los niveles clásicos del análisis lingüístico, of reciendo una descripción de la lengua de una forma que no se hubiera hecho antes con los habituales análisis de corpus desde un enfoque lingüístico-textual. Las preguntas que se plantearon fueron: ¿cómo es y qué rasgos presenta el modelo de lengua de la AD? y, específicamente, ¿en qué se parece o diferencia este modelo lingüístico del modelo del lenguaje prefabricado de la producción propia y del doblaje?

Por una parte, contamos con los trabajos de Chaume (200I, 2004) para abordar el estudio de un guion audiodescrito (en adelante, GAD) desde los análisis lingüísticos de la oralidad prefabricada de producciones audiovisuales propias y dobladas, y, por otra, nos basamos, especialmente, en el estudio de la oralidad prefabricada para producciones propias de Baños (2009), con el que caracterizamos los rasgos lingüísticos del GAD partiendo de la concepción del mismo como un texto audiovisual escrito para ser locutado.

\section{LA AUDIODESCRIPCIÓN: HACIA UN MODELO DE ANÁLISIS LINGÜÍSTICO DE LA AD}

Dentro del campo de la Traducción Audiovisual, se encuentra la rama de traducción accesible o «traducción audiovisual accesible» (Díaz Cintas, 2007; Jiménez Hurtado, 2007b) la cual ha profundizado en las necesidades de los espectadores con discapacidad sensorial. La Norma UNE I53020, para la audiodescripción, la define como:

(...) el servicio de apoyo a la comunicación que consiste en el conjunto de técnicas y habilidades aplicadas con objeto de compensar la carencia de captación de la parte visual con- tenida en cualquier tipo de mensaje, suministrando una adecuada información sonora que la traduce o explica, de manera que el posible receptor discapacitado visual perciba dicho mensaje como un todo armónico y de la forma más parecida a como lo percibe una persona que ve (AENOR, 2005:4).

La AD constituye un proceso de traducción intersemiótica dado que el texto origen es un texto audiovisual en el que el producto final será un texto lingüístico, que solo podrá ser comprendido y correctamente deconstruido si se analiza en su interacción con el texto audiovisual. Las imágenes y los códigos de significación del texto audiovisual se recodifican en signos lingüísticos en el idioma del texto audiovisual (GAD más códigos iconográficos y fotográficos) o del espectador meta. En relación con este proceso, en nuestro trabajo repasamos las cuestiones sobre qué y cómo se audiodescribe, atendiendo a la norma de referencia española mencionada anteriormente, que fue redactada por una comisión creada ad hoc por miembros de la ONCE y algunos de los primeros audiodescriptores de nuestro país. Respecto al cómo, resultó interesante encontrarse con uno de los principales objetos de debate entre profesionales y académicos: la objetividad y la subjetividad del texto audiodescrito. En nuestro trabajo, nos limitamos a esbozar dicha discusión y a contrastar las pautas españolas con las que se siguen en otros países. Por el momento, el qué parece estar claro pero la forma de audiodescribir o el cómo dependerá de la norma del país y del criterio del audiodescriptor.

El trabajo de investigación que sustenta este artículo consistió en describir los niveles de la lengua de la AD a partir del modelo de oralidad prefabricada de producciones propias (textos nativos) aplicándolo a un determinado GAD, que es el producto resultante del proceso de 
traducción semiótica que se realiza durante la $\mathrm{AD}$, cuyo canal de comunicación será el acústico en forma de narración sonora. Este tipo de aná- lisis nos permitió aproximarnos al GAD desde una perspectiva diferente para comprobar qué rasgos lingüísticos comparten dos textos que son audiovisuales, prefabricados y escritos para ser hablados, pero con funciones y receptores diferentes.

A continuación, exponemos un resumen de los dos modelos que sirvieron para fundamentar dicho estudio según los niveles del análisis lingüístico fonético-prosódico, morfológico, sintáctico y léxico-semántico: el modelo de la lengua del doblaje y el discurso oral prefabricado de los textos audiovisuales de producción propia en español.

\section{La lengua del doblaje: la oralidad prefabricada o dubbese (Chaume, 2004)}

Por «oralidad prefabricada», se entiende «el modo oral no espontáneo» de los textos audiovisuales, es decir, un discurso pretendidamente espontáneo, pero elaborado, que compartirá numerosas características con el discurso oral espontáneo (al que pretende imitar), pero que cuenta con características propias de la escritura (Chaume, 200I, 2004). Para nuestro trabajo, contamos con la descripción que a lo largo de los años ha realizado Chaume (200I, 2004, 20I2) sobre el modelo de lengua de los textos de ficción doblados al español y al catalán.

De forma general, este modelo constituye un registro lingüístico propio que, como tal, contiene rasgos que se repiten o tienden a repetirse en todos los doblajes:

- Nivel fonético-prosódico: en los doblajes al español, se observa una articulación fonética tensa, pronunciación clara, se evita la reducción de consonantes y la adición de vocales de apoyo iniciales, se evita la elisión de enlaces intraoracionales, se acentúa la entonación y se evitan ambigüedades prosódicas, asimilaciones, disimilaciones y cacofonías.

- Nivel morfológico: existe una tendencia a ajustarse a la normativa lingüística como medida de protección de la lengua; por tanto, en los doblajes se evitarán agramaticalidades, se respetará el dialecto estándar de la lengua meta y no se reproducirá ningún rasgo del registro oral coloquial.

- Nivel sintáctico: en este nivel se observan normalmente tanto estructuras del discurso espontáneo como un orden gramatical canónico. No se observa la segmentación continua de enunciados ni la supresión de conectores y marcadores discursivos, como podría ser esperable en la lengua oral espontánea, pero sí la presencia de otros rasgos propios del discurso oral espontáneo.

- Nivel léxico-semántico: en los doblajes de películas y series de ficción destinadas a adultos, se permite el léxico informal, coloquial y vulgar de acuerdo con la audiencia y la traducción suele reflejar el tono del texto origen. Se trata de crear un registro oral expresivo y verosímil mediante el uso de los recursos propios de la lengua meta evitando tecnicismos, dialectalismos o términos no normativos.

\section{La oralidad prefabricada de los textos audiovisuales de producción propia en español (Baños, 2009)}

En sus trabajos, Baños (2004, 2009, 2014) ha dado un paso más en la descripción del modelo de lengua del doblaje al compararlo con el modelo de lengua de los textos audiovisuales de ficción de producción propia, es decir, la autora ha conseguido distinguir aquellos rasgos 
lingüísticos propios del doblaje de aquellos que son propios de la producción de ficción en español, de modo que a partir de sus investigaciones, es posible realizar una taxonomía de rasgos lingüísticos propios del modelo de lengua del doblaje, los propios de la ficción producida en español, y aquellos rasgos que comparten ambos modelos.

La oralidad prefabricada es una «característica intrínseca al texto audiovisual de la cultura meta, para textos tanto originales como traducidos» (Chaume, 200r: 87) de la que parte la caracterización de la lengua del doblaje y sus niveles, y, por ende, el modelo de oralidad prefabricada para producciones propias de Baños (2009) que delimita el marco teórico de este trabajo. Así, la autora distingue las siguientes características del modelo de lengua de la ficción rodada en español:

- Nivel fonético-prosódico: se observan marcas orales coloquiales condicionadas por la idiosincrasia del personaje y de los actores, articulación fonética relajada, pronunciación clara; marcas suprasegmentales que actúan de refuerzos argumentativos, valorativos y alargamientos fónicos o silábicos con valor pragmático; se emplea la entonación para dotar al discurso de efecto rítmico y expresividad, y se aprecian marcas dialectales en función del personaje.

- Nivel morfológico: la planificación del discurso permite evitar las marcas morfológicas propias del discurso oral espontáneo, tales como las concordancias agramaticales o las formaciones por analogía. También se detecta la redundancia pronominal o empleo de formas pronominales con valor afectivo para reproducir el registro oral coloquial.

- Nivel sintáctico: se observa una organización textual ordenada y continua en la exposición con estructuras sintácticas sencillas y breves.
Se procura evitar la discontinuidad propia del discurso oral espontáneo, se encuentran sintagmas suspendidos y reelaboraciones que dotarán de verosimilitud a los diálogos pero sin recargar el texto; reelaboraciones, vacilaciones y titubeos (no frecuentes en el doblaje de producciones ajenas); unión cerrada entre enunciados, abundancia de oraciones yuxtapuestas y coordinadas y de conectores pragmáticos, así como expresiones coloquiales de relleno, de apertura y cierre propias del registro coloquial. Prima un orden sintáctico canónico de las palabras pero se realzarán los elementos informativa o expresivamente más relevantes; se observa un alto grado de redundancia, de elipsis gramatical, contextual y alta referencia exofórica.

- Nivel léxico-semántico: se aprecia un léxico restringido y un amplio uso de comodines; creación léxica: léxico común sin abusar de tecnicismos, uso frecuente de neologismos formales y sufijación con valores semánticos y pragmáticos; se facilita la entrada de préstamos internos mientras que los préstamos externos se corresponderán con vocablos que designen productos exportados de otras culturas. A fin de transmitir expresividad, se observa una fuerte creatividad morfológica y léxica reflejada en el uso frecuente de frases y expresiones metafóricas, entre otros. Según el tipo de producción, existirá el uso de tacos y términos no normativos, aunque el guionista procurará no abusar de ellos; el léxico, dialectos y lengua estándar dependerán de los personajes ya que las características sociolectales y dialectales, reflejadas tanto en el nivel fonético-prosódico como en el léxico, desempeñarán un papel esencial en su caracterización. Respecto al grado de normalización, aunque se recomienda el uso de una lengua estándar, las producciones propias 
de ficción se caracterizan por la presencia de rasgos subestándar en el nivel léxico.

66

\section{Hacia un modelo de análisis lingüistico de la AD basado en la oralidad prefabricada de las producciones audiovisuales propias}

Más allá de las cuestiones normativas, existen algunas características condicionantes de la AD (AENOR, 2005; Jiménez Hurtado, 2007a; Ramos, 20I3;) que restringen su modelo de lengua, como la función comunicativa doble (adecuación al receptor prototípico y a la función comunicativa del texto original); la triple subordinación del GAD (a lo que ocurre en la pantalla, a la distribución de los silencios en el texto y a la cantidad de tiempo provista para cada espacio de silencio); y la no pretensión de imitar el habla espontánea pero sí de cumplir con las expectativas del espectador-oyente. Por lo tanto, antes de proceder al análisis, sugerimos, como hipótesis, que el modelo de análisis lingüístico de nuestro GAD debería contemplar:

- Aplicación de la norma de la RAE frente a las tendencias lingüísticas anómalas manifiestas en la oralidad espontánea en los textos escritos y orales.

- Empleo profundo y extenso de todos los recursos de los niveles léxico y sintáctico, al igual que en la oralidad prefabricada de productos audiovisuales de producción doméstica y de productos audiovisuales doblados.

- Mayor singularidad del nivel fonético-prosódico respecto a los guiones interpretados por actores, con menor o ninguna opción a la espontaneidad.

- Nivel léxico determinado por el texto origen (TO) (lo que ocurre en pantalla), no por el guion original.

- Nivel morfológico de rasgos similares a los dos modelos descritos.
- Nivel sintáctico determinado por las pautas de la Norma UNE 153020 y subordinado a los silencios del guion original.

\section{OBJETIVOS Y METODOLOGÍA}

Para abordar el análisis, empleamos un método descriptivo de corte exploratorio, con el que se pretendió comparar el modelo de lengua de la AD con el de los textos audiovisuales nativos. El marco de análisis se basa en el modelo de Baños (2009) con el que la autora estudió los rasgos del discurso oral prefabricado de producciones propias en español, partiendo de su investigación sobre la lengua del doblaje y el resultado de comparar los niveles lingüísticos (fonético-prosódico, morfológico, sintáctico y léxico) con los del guion de una serie española en versión original (Siete Vidas). Asimismo, incluimos el modelo del dubbese para comparar posteriormente nuestros resultados puesto que, por un lado, suponía el punto de partida del trabajo de Baños (2009) y, por otro, respondería a la pregunta acerca de a qué tipo de modelo de lengua (nativo o doblado) se asemejaría más la oralidad prefabricada de una AD y por qué.

El objetivo general de este estudio fue aproximarnos a una descripción del modelo de lengua de la audiodescripción de Ocho apellidos vascos y compararlo con el modelo de las producciones audiovisuales propias y las traducidas para el doblaje; los objetivos específicos fueron validar aquellos rasgos lingüísticos pertenecientes al lenguaje prefabricado de la producción propia y del dubbese que también aparecen en la $\mathrm{AD}$, refutar otros, señalar rasgos propios de la $\mathrm{AD}$, y comparar nuestro GAD con las directrices de la Norma UNE I53O2O. 


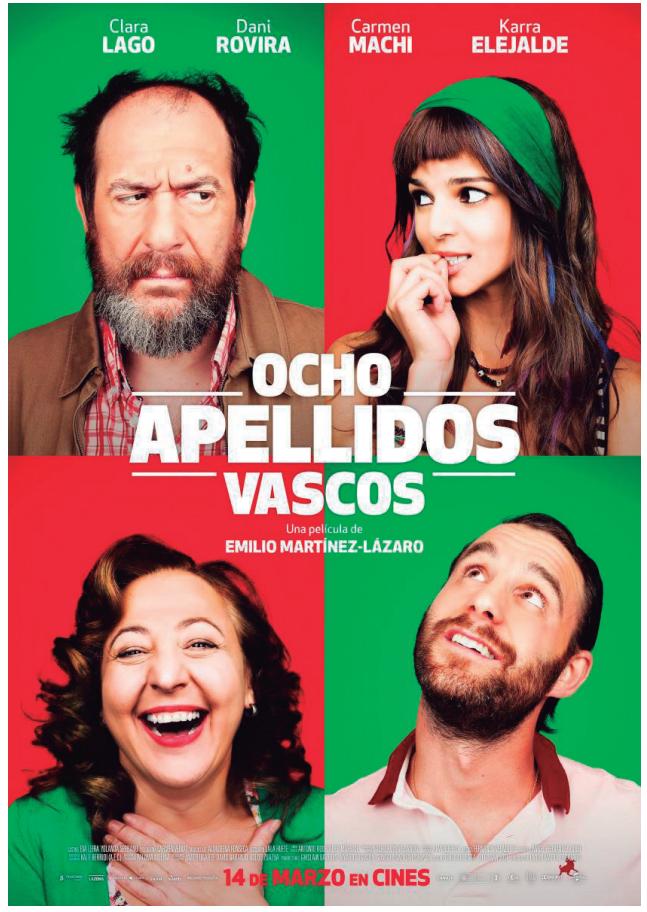

Objeto de estudio: criterio de selección del filme

El corpus utilizado para nuestra investigación fue el largometraje audiodescrito de producción española, Ocho apellidos vascos (Martínez Lázaro, 20I5).

Se trata de un corpus audiovisual monolingüe. De manera similar a la investigación en la que basamos parte de nuestro estudio, elegimos un filme cuyo guion original estuviera escrito en español (aunque a veces aparezcan enunciados y palabras en euskera) y de un perfil lo más parecido posible a la serie Siete Vidas. Respecto al modelo de lengua y género textual, se trata de una comedia romántica, con rasgos propios del español coloquial, con la salvedad de que muestra una fuerte presencia de rasgos dialectales o regionales y de ocasionales cambios de código lingüístico. El objeto de estudio cuenta con una duración de 95 minutos y una pertinencia destacada en el polisistema audiovisual español debido a su éxito entre los espectadores.

\section{Descripción del análisis}

Determinados el corpus audiovisual y el marco analítico, procedimos a transcribir el GAD manualmente en un documento Word con el fin de detectar los rasgos lingüísticos que contrastar con nuestro modelo base. Tras revisarlo junto con la audiodescripción de la película, analizamos el corpus transcrito y redactamos las 233 fichas en las que recogimos los rasgos destacados. Así, realizamos un análisis de carácter cualitativo (descriptivo) y contrastivo:

- Análisis cualitativo: identificación de los rasgos y ejemplificación de los casos más relevantes mediante fichas de trabajo.

- Análisis contrastivo mediante la comparación de los resultados con los rasgos característicos de la oralidad de los textos audiovisuales de producción propia y con los rasgos característicos de la oralidad de los textos audiovisuales de producción ajena (doblada).

\section{Fichas de análisis}

Para el análisis descriptivo, adaptamos la ficha de Baños (2009) de acuerdo con nuestro objeto de estudio tal y como describimos a continuación:

- Número de la ficha.

- Código de tiempo (TCR) para localizar el segmento al que nos referimos.

- Nivel del análisis lingüístico.

- Fragmento que destacamos.

- Texto.

A continuación (tabla I), se muestra un ejemplo representativo de una ficha descriptiva de las 233 redactadas. 
Tabla 1. Ficha de análisis cualitativo

\begin{tabular}{ll} 
FICHA & 45 \\
\hline TCR & OO:I5:I7 \\
\hline NIVEL & FRAGMENTO \\
\hline
\end{tabular}

SINTÁCTICO

Deixis espacial (frase).

En el pueblo de Argoitia. Dos jóvenes juegan a pelota en el frontón de la plaza.

Coordinación (y).

El microbús entra en la plaza y se detiene junto al frontón.

Uso del gerundio.

Yuxtaposición (coma). Coordinación (y). Perífrasis Rafael baja llevando una pequeña mochila al hombro, verbales: (volver a + inf., comenzar a + inf.).

Sujeto omitido.

Observa una gran pintada sobre una fachada donde

Subordinación de lugar (donde).

Yuxtaposición (dos puntos).

Uso del imperativo subordinado al To. dice en euskera: Utzi pakean Euskal Herria / Dejad en paz al País Vasco.

Sujeto omitido. Perífrasis verbal (seguir + gerun-

Sigue caminando por el pueblo, mirando los carteles

dio). Yuxtaposición (coma). Coordinación (y). Uso

del gerundio.

con los nombres de las calles y cotejándolos con el del DNI de Amaia.

Sujeto omitido (Argoitia).

Es un pueblo de antiguas y bellas casas de piedra con tejados inclinados.

Frase. Verbo elidido (es de solo...).

La mayoría de ellas de solo dos o tres alturas.

Sujeto omitido. Coordinación (y).

Subordinación (que).

Yuxtaposición (coma).

Llega frente a una de las casas $\mathbf{y}$, tras comprobar que coincide el nombre de la calle, se dirige hacia la puerta, deja su mochila en el suelo y saca el bolso de Amaia.

Sujeto omitido. Uso del gerundio.

Llama golpeando la aldaba del portón de madera.

\section{MORFOLÓGICO}

Uso de la construcción «a pelota» típico del espa- Dos jóvenes juegan a pelota... ñol del País Vasco.

Colocación del adjetivo. pequeña mochila; antiguas y bellas casas de piedra.

\section{LÉXICO}

Repetición redundante del sustantivo.

Frontón.

Única vez que dice el nombre completo.

Rafael

Préstamo externo.

euskera 


\section{FONÉTICO-PROSÓDICO}

Entonación sujeta a la puntuación; lectura de un cartel. ...una fachada donde dice en euskera: Utzi pakean

Euskal Herria...

\section{TEXTO}

En el pueblo de Argoitia. Dos jóvenes juegan a pelota en el frontón de la plaza. El microbús entra en la plaza y se detiene junto al frontón. Rafael baja llevando una pequeña mochila al hombro, vuelve a mirar el DNI de Amaia y comienza a caminar. Observa una gran pintada sobre una fachada donde dice en euskera: Utzi pakean Euskal Herria / Dejad en paz al País Vasco. Sigue caminando por el pueblo, mirando los carteles con los nombres de las calles y cotejándolos con el del DNI de Amaia. Es un pueblo de antiguas y bellas casas de piedra con tejados inclinados. La mayoría de ellas de solo dos o tres alturas. Llega frente a una de las casas y, tras comprobar que coincide el nombre de la calle, se dirige hacia la puerta, deja su mochila en el suelo y saca el bolso de Amaia. Llama golpeando la aldaba del portón de madera.

Tabla 2. Ficha de análisis contrastivo

\begin{tabular}{lll}
\hline & \multicolumn{2}{l}{ Modelo de lengua de AD } \\
\cline { 3 - 3 } Rasgos de la oralidad prefabricada en producciones propias (Baños, 2009) & Sí & \\
\hline
\end{tabular}

Después de transcribir y revisar el GAD, lo analizamos en función de los cuatro niveles de lengua mencionados anteriormente. Una vez terminado el proceso, pasamos al análisis contrastivo mediante la comparación de los resultados con la caracterización de la lengua de producciones propias y dobladas a fin de determinar el grado de similitud existente entre los rasgos de estos modelos y los del GAD. Para ello, empleamos cuadros resúmenes como el que se muestra en la tabla 2

En la columna de la derecha, añadimos el campo MODELO DE LENGUA DE LA AD y en la fila siguiente dividimos el espacio en los campos Sí, NO, AD. Cuando marcamos una $\mathrm{x}$ (equis) en sí, se trataba de un rasgo que aparecía recurrentemente en las fichas del análisis cualitativo de la lengua de la $\mathrm{AD}$; cuando se marcó NO, se trataba de un rasgo refutado o no encontrado, y cuando se marcó $\mathrm{AD}$, se trataba de un rasgo propio del lenguaje de la audiodescripción. En algunos casos, se marcó la casilla sí junto con $\mathrm{AD}$, lo significa que se trataba de un rasgo compartido con el GAD pero matizado por la idiosincrasia de la audiodescripción.

\section{ANÁLISIS Y RESULTADOS}

Realizamos un análisis exhaustivo de nuestro GAD en los cuatro niveles lingüísticos. Tras comparar los resultados con los modelos de lengua de la oralidad prefabricada para producciones propias y de doblaje, pudimos definir los rasgos específicos de la AD y validar o refutar aquellos de los distintos modelos. Finalmente, comparamos nuestros resultados con las pautas de la Norma UNE 153020 para determinar la coincidencia o no de cada nivel con las directrices de AENOR. 
Tabla 3

Análisis contrastivo fonético-prosódico para oralidad prefabricada en producciones audiovisuales propias y AD

Rasgos de la oralidad prefabricada en producciones propias (Baños, 2009)

sí

NO

$\mathrm{AD}$

Marcas orales coloquiales condicionadas por la idiosincrasia de cada personaje

Articulación fonética relajada: pérdida de fonemas

Pronunciación clara para que se facilite la comprensión

Marcas suprasegmentales de refuerzo argumentativo y alargamiento fónico o silábico con valor pragmático

Tabla 4: Análisis contrastivo fonético-prosódico para oralidad prefabricada en doblaje y AD

\begin{tabular}{l|cc}
\hline & Modelo de lengua de AD \\
\cline { 2 - 3 } \multicolumn{1}{c}{ Rasgos de la oralidad prefabricada para el doblaje (Chaume, 2004) } & Sí & NO \\
\hline Articulación fonética tensa & $\mathrm{X}$ & \\
\hline Pronunciación clara & $\mathrm{X}$ \\
\hline $\begin{array}{l}\text { Se evita la reducción o caída de consonantes, se evita la adición de vocales de } \\
\text { apoyo iniciales o epentéticas }\end{array}$ & $\mathrm{X}$ \\
\hline Elisión de enlaces intraoracionales en la interpretación & & $\mathrm{X}$ \\
\hline Acentuación de la entonación & \\
\hline Se evitan ambigüedades prosódicas & $\mathrm{X}$ \\
\hline Se evitan asimilaciones o disimilaciones y cacofonías & $\mathrm{X}$ \\
\hline
\end{tabular}

A la hora de ilustrar los resultados, el número entre paréntesis que acompaña los ejemplos corresponde al número de ficha del conjunto.

\section{Análisis fonético-prosódico}

En el largometraje el locutor posee una voz masculina joven que, tal y como recomienda la Norma UNE, es neutra, sin dejar entrever ningún acento regional, con una dicción correcta. Detectamos un ejemplo de rasgo fonético subestándar, la dicción del fonema / $\mathrm{d} /$ implosivo al final de palabra por $/ \theta$ / que, aunque no sea especialmente destacable, sí invita a reflexionar sobre el tipo de acento preferido para locutar, que parece ser el modelo estándar de castellano septentrional, como ocurre en doblaje [(I) Sevilla en la actuali$\mathrm{dad}$, por la noche]. Solo hay un locutor durante toda la película, incluyendo los momentos de lectura de carteles o rótulos (aunque la norma UNE no lo especifica, es regla general utilizar la misma voz para toda la audiodescripción).

En las tablas 3 y 4 se muestran los cuadrosresumen del análisis contrastivo.

En cuanto la acentuación de la entonación, solo se produce en un caso de 233 intervenciones con el fin de imprimir afectividad [(224) Vuelve 
a girarse... y se funde con su padre en un largo abrazo)]. En el resto de intervenciones responde a causas como cambios de entonación al presentar una intervención, cambios relacionados con la puntuación gramatical, pausas en la $\mathrm{AD}$ coincidentes con puntos suspensivos o cambios de escena y pausas en el discurso por indicación de la Norma (los efectos sonoros significativos o breves intervenciones durante un hueco de un mensaje deben mantenerse como referencia sonora en el GAD), ej.: (155) Koldo señala el cajón donde guardaron las cosas de Rafa [Canción de los del Río]. Va hacia la cómoda, Amaia se interpone.

\section{Resultados}

- Unión entre marcadores temporales y espaciales (deícticos) a causa de la velocidad de dicción en cambios de escenas.

- El discurso solo se interrumpe mediante pausas ligadas al desarrollo de la acción y para permitir la escucha de efectos sonoros cumpliendo con la norma UNE I53020.

- La entonación no varía, independientemente de la puntuación gramatical (dos puntos ante la intervención de personajes, puntos suspensivos relacionados con pausas en la acción).

- El nivel fonético prosódico comparte más rasgos con el dubbese que con el modelo de producción propia (articulación fonética tensa, pronunciación clara, reducción o caída de consonantes, evitar ambigüedades prosódicas, asimilaciones o disimilaciones y cacofonías, entre otras).

En resumen, la pronunciación en $\mathrm{AD}$ cumple con los requisitos de la norma AENOR por el carácter de texto audiovisual leído y se asemeja a la oralidad prefabricada de los textos audiovisuales de ficción para el doblaje. La entonación en la $\mathrm{AD}$ suena más artificial que en los textos de ficción de producción propia y de doblaje, puesto que no tiene que cumplir con la expectativa de la naturalidad. Una característica fonéticoprosódica en nuestra aproximación al modelo de lengua es que no hay lugar para la interpretación, se trata de un texto escrito para ser locutado sin inflexiones, impostaciones o variaciones de la voz a diferencia de los guiones del resto de producciones audiovisuales. Además, otro elemento fundamental que caracteriza a este nivel es la restricción del tiempo disponible para describir. Por último, no se aprecian variaciones en la entonación, posiblemente para no transmitir subjetividad a través de este rasgo del lenguaje.

\section{Análisis morfológico}

En AD el interés radica en presentar un lenguaje correcto y cuidado en términos normativos, sobre todo, teniendo en cuenta su carácter de texto escrito, planificado, que sirve como medio de difusión de la lengua con función educativa. Además, tras el análisis resultó interesante detectar la frecuente colocación antepuesta de los adjetivos a modo de adjetivo explicativo con carácter literario. Encontramos I7 colocaciones de los adjetivos explicativos «literarios» vs. especificativos como, por ejemplo, largo túnel (3I), sinuosas carreteras (32), tradicional caserío (4I), espesa barba (66) o gran mostacho (2I2).

En las tablas 5 y 6 se muestran los cuadrosresumen del análisis contrastivo.

\section{Resultados}

Se trata del nivel en el que coinciden en sus rasgos la $\mathrm{AD}$, el modelo para producciones propias y el dubbese. Los tres presentan una morfología muy normativa y conservadora. La ausencia de redundancias coincide con lo indicado por la Norma.

- Muy normativo, no se incurre en agramaticalidades ni se reproduce ningún rasgo del registro oral coloquial. 
Tabla 5

Análisis contrastivo morfológico para oralidad prefabricada en producciones audiovisuales propias y AD

72

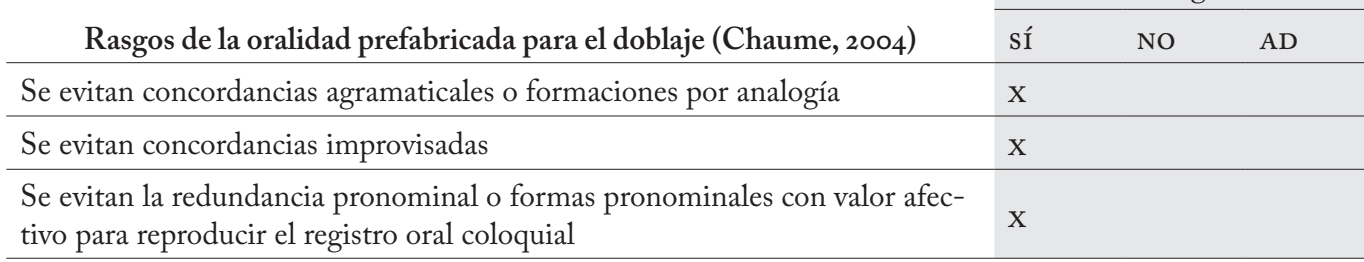

Tabla 6. Análisis contrastivo morfológico para oralidad prefabricada en doblaje y AD

\begin{tabular}{|c|c|c|c|}
\hline \multirow[b]{2}{*}{ Rasgos de la oralidad prefabricada en producciones propias (Baños, 2009) } & \multicolumn{3}{|c|}{ Modelo de lengua de AD } \\
\hline & sí & NO & $\mathrm{AD}$ \\
\hline Se evita cualquier tipo de agramaticalidad & $\mathrm{x}$ & & \\
\hline Respeto del dialecto estándar de la lengua meta & & & $\mathrm{X}$ \\
\hline Inexistencia de rasgos del registro oral coloquial o espontáneo & $\mathrm{x}$ & & \\
\hline
\end{tabular}

- Se utiliza la $3^{\mathrm{a}}$ persona del singular, como indica la norma UNE 153020 , y en ocasiones la $3^{\text {a }}$ persona del plural.

- Lenguaje con tendencia literaria, como rasgo propio.

\section{Análisis sintáctico}

La mayoría de los rasgos propios de la $\mathrm{AD}$ en cuanto a su sintaxis vienen determinados por la norma UNE, que exige el empleo de una sintaxis sencilla y una estructura gramatical prototípica cerrada. Este orden canónico de sujeto, verbo y predicado se cumple en el GAD, combinándose con sujetos elípticos o intervenciones en las que solo aparece un verbo o un verbo y su predicado, o en las que se modifica dicho orden ya sea para realzar la información o por restricciones de tiempo; ej.: (I44) Por una esquina aparecen los antidisturbios; (I89) Bajo el vestido de novia, lleva zapatillas de deporte; (2I2) Asombrado, se deja caer en el sofá; (33) Disimula.

En nuestro análisis, incluyendo bajo «sintaxis sencilla» las oraciones yuxtapuestas y coordinadas, detectamos tan solo 26 oraciones subordinadas y una oración terciopersonal [(I4) A Amaia se le cae el bolso al suelo], lo que simplifica aún más la sintaxis.

- Subordinación con que: (I4) ven explotar fuegos artificiales de diferentes formas y colores que iluminan toda la habitación; (I4) Amaia se quita el clavel rojo que todavía lleva sobre su cabeza y se deja caer bocabajo sobre la cama; (15) Rafa se inclina sobre ella y observa el rostro de Amaia que continúa dormida y...; (r6) Se ha pinchado en el pie con el clavel rojo que llevaba Amaia; (I8) Le quita la bandeja del desayuno que se acaba de preparar; (45) Llega frente a una de las casas y, tras comprobar que coincide el nombre de la 
calle; (32) algunos le miran muy serios excepto una mujer de unos 50 años que le saluda con la mano; (32) Continúa recorriendo las sinuosas carreteras de montaña que bordean el mar; (5I) solo consigue que la llama se haga más intensa; (5I) dice que llame a los bomberos; (66) Amaia coge su traje de novia y corre hasta su coche que, a su vez, es un taxi; (134) Los radicales adelantan a la cabecera de la manifestación que es en homenaje a un antiguo líder nacionalista; (I89) Se cruza con algunos vecinos que la miran asombrados; (I92) Amaia consigue soltarse el vestido de novia, que cae al suelo; (193) La imagen sobrevuela la pequeña ermita y los acantilados que hay junto a ella; (209) Sale Merche, a continuación, sale Amaia que se detiene en la entrada de la ermita; (II2) Se monta en el mismo microbús que le llevó hasta allí;

- Subordinación con aunque: (2) El local está muy animado, hay algunos turistas aunque la mayoría parecen* [sic.] locales; (32) Ha dejado de llover aunque el día continúa con el cielo encapotado;

- Subordinación con nexo de relativo (15) La joven continúa en la misma posición en la que cayó sobre la cama, hace algunas horas;

- Subordinación temporal: (30) Sigue estudiando el libro de euskera hasta que se queda dormido recordando las palabras de sus amigos; (I9I) esta sonríe divertida mientras le deja hacer;

- Subordinación espacial con donde: (3I) Circulan junto a un cartel donde se lee: Euskadi Ongi Etorri; (45) Observa una gran pintada sobre una fachada donde dice en euskera: Utzi pakean Euskal Herria; (Ioo) Está junto a la parada y el caserío donde se bajó la mujer del microbús; (I5I) Koldo señala el cajón donde guardaron las cosas de Rafa.
En cuanto a la unión entre enunciados, en $\mathrm{AD}$ no aparecen los conectores pragmáticos o argumentativos característicos de la oralidad prefabricada de la producción propia y del doblaje (¿eh?, oye, es que, bueno, pues...). La posición de los marcadores o deícticos temporales y espaciales, siempre en primera posición o en primera y segunda posición al inicio de una frase, es una característica del lenguaje de la AD. Estas frases o complementos se emplean entre escenas para situar o informar al espectador; es esta función referencial la que aporta coherencia y cohesión a la descripción. Además, el uso obligatorio de referentes es intencionado y de suma importancia, ya que el espectador ciego solo puede apoyarse en el código lingüístico que está escuchando para ver la película. Por último, como rasgo destacado de la $\mathrm{AD}$, se puede comprobar que los deícticos «aquí y ahora» no se reproducen en el GAD, puesto que el espectador ciego no puede ver dicha referencia en pantalla. Con referencia a la elipsis (solo gramatical), en ocasiones se eliden verbos y preposiciones al igual que en el lenguaje oral prefabricado, por ejemplo: (43) La mujer al conductor (verbo elidido: se dirige) o (216) Su móvil (verbo elidido: suena).

En las tablas 7 y 8 se muestran los cuadrosresumen del análisis contrastivo.

\section{Resultados}

El nivel sintáctico refleja la estructura del GAD sobre la que se asienta el léxico que trasmite el significado. Se trata del nivel más detallado en los modelos de oralidad prefabricada propia y ajena al igual que en nuestro estudio:

- La sintaxis es sencilla y convencional con estructuras gramaticales prototípicas (cerradas y ordenadas).

- Se sigue un orden canónico, con omisión del sujeto de la misma manera que ocurre en el habla natural, así como elisión de algunas 
Tabla 7

Análisis contrastivo sintáctico para oralidad prefabricada en producciones audiovisuales propias y AD

\begin{tabular}{|c|c|c|c|}
\hline \multirow[b]{2}{*}{ Rasgos de la oralidad prefabricada en producciones propias (Baños, 2009) } & \multicolumn{3}{|c|}{ Modelo de lengua de $\mathrm{AD}$} \\
\hline & sí & No & $\mathrm{AD}$ \\
\hline Sintaxis sencilla debido a la planificación & $\mathrm{x}$ & & \\
\hline $\begin{array}{l}\text { Estructura gramatical cerrada y ordenada, alejada de los rasgos propios del } \\
\text { discurso oral espontáneo }\end{array}$ & $\mathrm{X}$ & & \\
\hline Organización textual & sí & NO & $\mathrm{AD}$ \\
\hline Estructura generalmente ordenada y continuidad en la exposición & $\mathrm{x}$ & & \\
\hline Estructuras sintácticas sencillas y breves & $\mathrm{x}$ & & \\
\hline Se trata de evitar la discontinuidad del discurso oral espontáneo & $\mathrm{x}$ & & \\
\hline $\begin{array}{l}\text { Sintagmas suspendidos y reelaboraciones para dotar de verosimilitud a los } \\
\text { diálogos }\end{array}$ & & $\mathrm{x}$ & \\
\hline Unión cerrada entre enunciados & sí & NO & $\mathrm{AD}$ \\
\hline Enlaces sintácticos entre enunciados menos fuertes que en la escritura & & & $\mathrm{x}$ \\
\hline $\begin{array}{l}\text { Abundancia de enunciados yuxtapuestos y coordinados, y de conectores } \\
\text { pragmáticos }\end{array}$ & & & $\mathrm{x}$ \\
\hline $\begin{array}{l}\text { Expresiones coloquiales de relleno, de apertura y cierre propias del registro } \\
\text { coloquial }\end{array}$ & & $\mathrm{x}$ & \\
\hline $\begin{array}{l}\text { Discurso más cohesionado que el oral espontáneo, con mecanismos de cohe- } \\
\text { sión propios }\end{array}$ & & & $\mathrm{x}$ \\
\hline Orden de las palabras & sí & NO & $\mathrm{AD}$ \\
\hline $\begin{array}{l}\text { Orden sintáctico canónico y realce de elementos más relevantes informativa } \\
\text { o expresivamente }\end{array}$ & $\mathrm{X}$ & & \\
\hline $\begin{array}{l}\text { Alto grado de redundancia en los diálogos para emular el registro oral } \\
\text { espontáneo }\end{array}$ & & $\mathrm{x}$ & \\
\hline Elipsis gramatical y contextual y alta referencia exofórica & sí & NO & $\mathrm{AD}$ \\
\hline Empleo de la elisión verbal y, con menos frecuencia, a la preposicional & $\mathrm{x}$ & & $\mathrm{x}$ \\
\hline $\begin{array}{l}\text { Empleo abundante de unidades anafóricas con referencia en pantalla y de } \\
\text { deícticos temporales y espaciales (aquí y ahora) }\end{array}$ & & & $\mathrm{x}$ \\
\hline $\begin{array}{l}\text { Estrategias para aproximar las intervenciones de los actores al discurso } \\
\text { espontáneo: elipsis, realce de elementos, etc. }\end{array}$ & & $\mathrm{x}$ & \\
\hline Mecanismos para imprimir discontinuidad al discurso & & $\mathrm{x}$ & \\
\hline Reelaboraciones, vacilaciones y titubeos & & $\mathrm{x}$ & \\
\hline
\end{tabular}


Tabla 8. Análisis contrastivo sintáctico para oralidad prefabricada en doblaje y AD

\begin{tabular}{|c|c|c|c|}
\hline \multirow[b]{2}{*}{ Rasgos de la oralidad prefabricada para el doblaje (Chaume, 2004) } & \multicolumn{3}{|c|}{ Modelo de lengua de AD } \\
\hline & sí & NO & $\mathrm{AD}$ \\
\hline Estructuras y rasgos similares a los del discurso espontáneo & & $\mathrm{x}$ & \\
\hline $\begin{array}{l}\text { Orden gramatical canónico, sin marcas del registro oral como vacilaciones, } \\
\text { hipérbatos, anacolutos, etc. }\end{array}$ & $\mathrm{x}$ & & \\
\hline $\begin{array}{l}\text { Segmentación continua de un enunciado, supresión de conectores y marca- } \\
\text { dores discursivos sin conexión gramatical en forma de opinión }\end{array}$ & & $\mathrm{x}$ & \\
\hline $\begin{array}{l}\text { Rasgos propios del discurso oral espontáneo como enunciados yuxtapuestos } \\
\text { coordinados, muletillas, interjecciones o vocativos }\end{array}$ & & $\mathrm{x}$ & \\
\hline
\end{tabular}

partículas (preposiciones, verbos, sustantivos) que dotan a la AD de naturalidad.

- No hay discontinuidad en el discurso y, cuando se produce, obedece a la acción de la película y se refleja mediante la prosodia.

- Uso predominante del presente de indicativo; uso escaso del presente continuo. En el caso de las alteraciones en el discurso narrativo, aparecen los tiempos presente perfecto, pretérito indefinido e imperfecto de indicativo.

- Abundante uso de la yuxtaposición (punto; coma) y coordinación descrito en el conjunto de fichas. Poco uso de oraciones subordinadas (solo 26 casos). Aparición de verbos en solitario debido a restricciones de tiempo.

- Abundante presencia de frases empleadas como marcadores temporales y espaciales, complementos circunstanciales de tiempo (CCT) y complementos circunstanciales de lugar (CCL) utilizados en $\mathrm{I}^{\mathrm{a}}$ posición (topicalización) para focalizar la atención en el tiempo y el espacio de la acción. Actúan de nexos entre cambios de escenas, para situar al espectador.

- Los marcadores temporales y espaciales (frases o CCT y CCL) así como algunos sin- tagmas descriptivos, aparecen en las primeras posiciones de la oración como marca la norma UNE I53020.

- Errores comunes en el uso del español que se transfieren a la lengua escrita (le/les*).

En este nivel destaca un rasgo característico de la $\mathrm{AD}$, el uso de marcadores temporales y espaciales en el orden que marca la norma UNE. Los conectores pragmáticos típicos de los modelos de oralidad prefabricada propia y ajena no aparecen en $\mathrm{AD}$. Este es el nivel donde el dubbese y la AD más difieren; en un GAD no se encuentra ningún rasgo que se salga de una estructura cerrada y planificada o que se aproxime al lenguaje oral espontáneo.

De acuerdo con la norma UNE, respecto a «qué se audiodescribe», la información debe aparecer en el orden «cuándo», «dónde», «quién», «qué» y «cómo». Tras nuestro análisis, creemos que el empleo de frases en el GAD funciona como respuesta a estas preguntas. Asimismo, nos llamó la atención que en todos los casos en los que aparecían juntos un marcador temporal y de lugar (los más abundantes), nuestro corpus confirmaba el orden propuesto con una excepción: 
(72) Poco después, en comisaria.

(8I) Por la noche, en la barra de un asador.

(155) Después, en el salón.

(I9I) Más tarde. En la casa.

(2I2) Por la mañana. En el caserio de Merche... Excepción:

(I) Sevilla, en la actualidad, por la noche. ( ${ }^{\circ}$ espacial, $2^{\circ}$ temporal).

También se apreciaron tres oraciones impersonales a modo de deixis temporal o espacial:

(3I) Ha amanecido (...).

(99) Es noche cerrada.

(IO5) (...) Es un cuarto de baño.

\section{Análisis léxico-semántico}

Una característica del léxico de un GAD es el empleo de expresiones gráficas, vívidas que describan la acción como, por ejemplo: llevar en volandas (I2), cerrar en las narices (5I), frenar en seco (II2), salir cabizbajo $(205,225)$ o fundirse en un largo abrazo (223), entre otras. Además, la precisión léxica se observa en el uso de verbos específicos, a menudo con su complemento correspondiente como: $(3,22 \mathrm{I})$ apurar (una bebida), (I2) forcejear, (I6) esbozar una sonrisa, (30, 66) lucir barba, (3I) restallar o asentir sin convicción (34). Cabe mencionar el profuso empleo de verbos de movimiento (descender, alejarse, dirigirse, inclinarse, incorporarse, aproximarse, asomarse, avanzar, atravesar, encaminarse) y de verbos de percepción (mirar, mirarse, observar, ver) acompañados de complementos (con desgana, embelesado, fijamente, cómplice, mosqueado, achispado, etc.) que contribuyen dotando de mayor variedad y precisión al lenguaje de la AD.

En cuanto a la creación léxica, no se encuentra ningún tipo de neologismo ni sufijación con valores semánticos ni pragmáticos a excepción de dos sufijos o diminutivos con valor semántico, braguitas (I4 y I5) y mesilla (2II). Del mismo modo, el rasgo que alude al empleo de préstamos internos y voces de distintos lenguajes especiales y del argot (juvenil y delictivo) queda refutado, si bien la norma UNE acepta su uso cuando se trata de la lectura de un subtítulo o gráfico ofensivo. En cambio, sí se destaca el uso de un léxico específico relacionado con el contexto folclórico andaluz, en el que se desarrolla parte de la película, como: guirnaldas (2), farolillos (2), señoritos andaluces (2), tablao flamenco (2), noche sevillana (I4), palmeros (2 y 227), traje corto (3), traje de flamenca (I4), faralaes (3), rebujito (3), pendientes de flamenca (I5), calesa (227, 230, 23I, 232) y los del Río (227); y referencias al País Vasco, como: caserío (4I, 44, 49, I02. 209, 2II), jugar a pelota (45), frontón (45) y Athletic de Bilbao (85).

No se da lugar a la creatividad léxica ya que en $\mathrm{AD}$ se representa lo que se ve y se evitan alusiones a otra realidad distinta a la presente. Si en dubbese el léxico dota de verosimilitud a la traducción, en AD el léxico la dota de significado mediante la traducción de los códigos semióticos a palabras en el GAD. El empleo de un registro oral expresivo y verosímil se valida pero matizado por el requisito de la AD de utilizar un léxico rico y preciso, dentro de sus restricciones propias, es decir, sin la presencia de rasgos del lenguaje oral espontáneo como interjecciones, muletillas o palabras vacías.

El único rasgo coincidente con el modelo de Baños (2009) se refiere al uso de préstamos externos. Estos se corresponden con vocablos del léxico y la cultura vasca reconocibles y 
empleados en el resto de España. Se localizan ocho préstamos (se indica únicamente la primera ficha en la que aparecen): ikurriña (26), euskera (30), ertzainas (5I), borroka/s (55), abertzale/s (59), chacolí (I47), txapela (I79), chiquito (220).

En las tablas 9 y ro se muestran los cuadrosresumen del análisis contrastivo.

\section{Resultados}

- Precisión y riqueza léxica, especialmente en verbos, adjetivos y adverbios.

- No se aprecia creatividad léxica ni el uso de metáforas para evitar la subjetividad.

- Lengua estándar, en un registro formal.

- Léxico determinado por el To (lo que ocurre en pantalla), no por el guion original.

- Comparado con el modelo de lengua para producciones propias, solo coinciden en el uso de préstamos externos de uso aceptado y justificado.

Tabla 9

Análisis contrastivo léxico-semántico para oralidad prefabricada en producciones audiovisuales propias y AD

\begin{tabular}{|c|c|c|c|}
\hline \multirow[b]{2}{*}{ Rasgos de la oralidad prefabricada en producciones propias (Baños, 2009) } & \multicolumn{3}{|c|}{ Modelo de lengua de AD } \\
\hline & sí & No & $\mathrm{AD}$ \\
\hline $\begin{array}{l}\text { Las normas tácitas que aconsejan evitar palabras ofensivas, tecnicismos o } \\
\text { dialectalismos no pesan tanto en el discurso oral propio }\end{array}$ & & $\mathrm{x}$ & \\
\hline Léxico restringido y amplio uso de comodines & & $\mathrm{x}$ & \\
\hline Creación léxica & sí & NO & $\mathrm{AD}$ \\
\hline $\begin{array}{l}\text { Frecuente uso de neologismos formales, sufijación con valores semánticos y } \\
\text { pragmáticos }\end{array}$ & & $\mathrm{x}$ & \\
\hline $\begin{array}{l}\text { Préstamos internos, entrada de neologismos y voces de distintos lenguajes } \\
\text { especiales y del argot }\end{array}$ & & $\mathrm{x}$ & \\
\hline Léxico común sin abusar de tecnicismos & & & $\mathrm{x}$ \\
\hline $\begin{array}{l}\text { Préstamos externos correspondientes a vocablos para designar productos } \\
\text { exportados de otras culturas }\end{array}$ & $\mathrm{x}$ & & \\
\hline Expresividad y creatividad léxica & sí & No & $\mathrm{AD}$ \\
\hline $\begin{array}{l}\text { Fuerte creatividad morfológica y léxica reflejada en el uso de frases y metáfo- } \\
\text { ras; fórmulas del registro oral coloquial }\end{array}$ & & $\mathrm{x}$ & \\
\hline Tacos y términos no normativos & & $\mathrm{X}$ & \\
\hline Léxico, dialectos y lengua estándar & sí & NO & $\mathrm{AD}$ \\
\hline $\begin{array}{l}\text { Las características sociolectales y dialectales desempeñan un papel esencial } \\
\text { en la caracterización de los personajes }\end{array}$ & & & $\mathrm{x}$ \\
\hline $\begin{array}{l}\text { Las producciones propias de ficción se caracterizan por la presencia de ras- } \\
\text { gos subestándar en el nivel léxico }\end{array}$ & & $\mathrm{x}$ & \\
\hline
\end{tabular}


Tabla 10. Análisis contrastivo léxico-semántico para oralidad prefabricada en doblaje y AD

\begin{tabular}{|c|c|c|c|}
\hline \multirow[b]{2}{*}{ Rasgos de la oralidad prefabricada para el doblaje (Chaume, 2004) } & \\
\hline & sí & NO & $\mathrm{AD}$ \\
\hline Uso de léxico que dota de verosimilitud a la traducción & & & $\mathrm{x}$ \\
\hline $\begin{array}{l}\text { Uso de la intertextualidad, del argot y figuras estilísticas como comparacio- } \\
\text { nes, metáforas, dobles sentidos, etc. }\end{array}$ & & $\mathrm{x}$ & \\
\hline $\begin{array}{l}\text { El léxico informal, coloquial y vulgar se permite de acuerdo con la audiencia; } \\
\text { la norma es reflejar el tono del To }\end{array}$ & & & $\mathrm{X}$ \\
\hline $\begin{array}{l}\text { Registro oral expresivo y verosímil mediante recursos de la lengua meta; se } \\
\text { evitan tecnicismos, dialectalismos o términos no normativos }\end{array}$ & $\mathrm{X}$ & & $\mathrm{X}$ \\
\hline
\end{tabular}

- Comparado con el dubbese, coincide en un registro oral expresivo y verosímil ciñéndose a los recursos léxicos de la lengua, evitando tecnicismos, dialectalismos y términos no normativos.

Este es uno de los niveles más productivos en la confección de un GAD y más ilustrativos en su locución. Es en el léxico donde recae todo el peso de la AD puesto que, en definitiva, un GAD se compone de palabras que transmiten la información de lo que está ocurriendo en pantalla y que contienen el significado traducido del resto de códigos audiovisuales del lenguaje cinematográfico de la película.

El léxico es pieza clave de la $\mathrm{AD}$, ya que las palabras dotan de significado al discurso al portar la información icónica a través del canal acústico. Respecto a los préstamos externos, en nuestro corpus coincidía que, por la temática de la película, se usan bastantes términos del euskera aceptados y utilizados indistintamente por los hablantes de español. No existe ningún tipo de relación entre el léxico y los personajes puesto que en AD solo hay un locutor, no actores, y los rasgos fonético-prosódicos no reflejarán nada que se salga de la norma UNE.

\section{CONCLUSIONES}

En esta investigación se tuvieron en cuenta dos premisas significativas: por un lado, para utilizar el modelo de Baños (2009) con el fin de describir la lengua de las producciones audiovisuales propias, nos pareció más adecuado elegir la audiodescripción de un texto origen en versión original española $y$, por otro, al ser la $\mathrm{AD}$ un modelo lingüístico que se aplica a un texto doméstico o nativo (como además indica la norma UNE), sería más adecuado compararla con este modelo que con el del doblaje. Sin embargo, tras el análisis de los resultados, encontramos que, con la excepción del nivel sintáctico, el modelo de lengua de la $\mathrm{AD}$ se acerca más al modelo del dubbese o producciones dobladas que al de producción propia, lo que consideramos el principal hallazgo a nivel general de este estudio.

Un nivel que arrojó resultados interesantes en su descripción fue el fonético-prosódico: el principal rasgo que caracteriza a la $\mathrm{AD}$ respecto al resto de modelos es que el locutor/a es la única voz que interviene durante los silencios de la película. Este nivel está interrelacionado con el léxico puesto que, fundamentalmente, las palabras no tienen la función de caracte- 
rizar al personaje. Encontramos otros rasgos que nos llamaron la atención por disentir de la Norma, por ejemplo, los casos en que apreciamos afectividad o una entonación particular en la descripción de una escena con el fin de reforzar la transmisión de información por medio de las palabras. Finalmente, cabe destacar que los resultados del análisis manifestaron la similitud existente en este nivel entre la AD y el dubbese. Particularmente, consideramos que en este nivel tanto la competencia lingüística como los recursos léxicos que posea el traductor/ descriptor son muy importantes.

Como señalamos en la propuesta de análisis de la AD, el nivel léxico viene determinado por el texto origen (lo que se ve en pantalla), no por el guion original. Destaca un léxico rico y preciso, sin rasgos subestándar ni empleo de palabras vacías o comodines. Dado que la película seleccionada menciona constantemente referentes culturales, esto se manifiesta en la elección de las palabras que los designan. Observamos la importancia del léxico en $\mathrm{AD}$, ya que es el medio para narrar los hechos durante silencios largos (que suelen corresponderse con transiciones entre escenas) y para describir brevemente las acciones significativas en una escena, durante los silencios disponibles.

En cuanto al nivel sintáctico, destacan fundamentalmente dos aspectos: el empleo de una sintaxis sencilla con un número reducido de oraciones subordinadas frente a la abundancia de sintagmas nominales, oraciones yuxtapuestas con punto, coma, y oraciones coordinadas; y el uso abundante de marcadores temporales y espaciales como frases o complementos circunstanciales que sirven para situar al espectador y presentar la información con un orden determinado (el cuándo y dónde de la acción).

En el plano morfológico, destaca la tendencia a imprimirle un cariz literario al texto audio- descrito mediante la colocación antepuesta de los adjetivos en función explicativa; sin duda, la influencia del lenguaje literario en el GAD como prototipo textual. Asimismo, el análisis reveló el inherente carácter normativo de los textos de ficción, ya sea un guion para producción propia, doblaje o un GAD. En el caso de este último, la corrección morfosintáctica, léxica e incluso prosódica no permite ninguna agramaticalidad ni muestras del lenguaje oral espontáneo. En el nivel morfológico solo detectamos una sola concordancia ad sensum, agramatical. La principal incorrección recurrente que detectamos fue en el nivel sintáctico, el leísmo, y en este caso se trata de un uso equivocado extendido en muchas zonas del español peninsular.

Como último apunte, constatamos que en cada nivel se refrendan la mayoría de las recomendaciones de la Norma UNE 153020 con algunas excepciones, como el uso del lenguaje cinematográfico, ya que identificamos expresiones como «a vista de pájaro», «la imagen sobrevuela» o «funde a negro». Si bien este tipo de lenguaje no se debe emplear durante la $\mathrm{AD}$, en nuestro GAD lo encontramos en casos utilizados para situar al espectador en el texto (la escena) o dar información al principio o al final de la película.

En conclusión, creemos que sería muy recomendable aprovechar este trabajo para replicar este tipo de estudio, bien con una mayor muestra de filmes que permitan la validación de los resultados, bien para describir la lengua de la AD de una producción doblada al español y comparar los resultados con los de nuestro modelo para producciones audiovisuales nativas. Para ello, sería necesario replicarlo mediante un sistema digital de etiquetado de corpus que permita una clasificación sistemática y una rápida búsqueda de resultados. Además, sería sumamente interesante profundizar en la investigación del nivel 
fonético-prosódico para el que apenas existen descripciones de los rasgos en $\mathrm{AD}$.

La audiodescripción es un campo apasio80 nante con numerosas cuestiones pendientes de ser tanto investigadas como consensuadas por investigadores, académicos y profesionales. Esperamos que los hallazgos resultantes aporten continuidad a los trabajos que se están llevando a cabo para satisfacer las necesidades de la población ciega y con discapacidad visual que es, en definitiva, la razón de ser de esta modalidad de traducción accesible.

RECIBIDO EN ENERO DE $20 I 7$ ACEPTADO EN SEPTIEMBRE DE 2018 VERSIÓN FINAL DE SEPTIEMBRE DE 2018

\section{BIBLIOGRAFÍA}

Aenor (2005): Norma UNE I53030: Audiodescripción para personas con discapacidad visual. Requisitos para la audiodescripción y elaboración de audioguías, Madrid.

Arcos Urrutia, Juan Manuel (20I2): «Análisis de guiones audiodescritos y propuestas para la mejora de la norma UNE I53020", Tonos, Revista electrónica de estudios filológicos, 22, <https:// www.um.es/tonosdigital/znum22/secciones/ estudios-05-la_audiodescripcion.htm> [consulta: IO-IX-20I5].

Baños Piñero, Rocío (2004): «La oralidad prefabricada en los textos audiovisuales: estudio descriptivo-contrastivo de Friends y Siete Vidas», Fòrum de recerca, Io, <http://hdl.handle.net/Io234/79126> [consulta: I9-IX-20I5].

- (2009): La Oralidad prefabricada en la Traducción para el Doblaje: Estudio descriptivo-contrastivo del español de dos comedias de situación: Siete Vidas y Friends. Universidad de Granada, Departamento de Traducción e Interpretación. Tesis doctoral, <http://hera.ugr.es/tesisugr/I83I93I2.pdf> [consulta: I7-IX-20I5].

- (2014): «Orality Markers in Spanish Native and Dubbed Sitcoms: Pretended Spontaneity and Prefabricated Orality», META, 592, 406-435, doi: I0.7202/1027482ar.
BOE (2010): «Ley General Audiovisual», Boletín Oficial del Estado, 79, <https://www.boe.es/buscar/pdf/2010/BOE-A-2oIO-5292-consolidado. pdf $>$ [consulta: II-IX-20I5].

CESyA (20I4): Seguimiento del subtitulado y la audiodescripción en la TDT, Madrid: Universidad Carlos III, <http://www.cesya.es/sites/default/files/ documentos/InformeAccesibilidadTDT2or4. pdf $>$ [consulta: I5-IX-2IO5].

Chaume, Frederic (200I): «La pretendida oralidad de los textos audiovisuales y sus implicaciones en traducción», en Agost, R. y F. Chaume (eds.), La traducción en los medios audiovisuales, Castellón de la Plana: Publicaciones de la Universitat Jaume I, 77-88.

- (2004): Cine y Traducción, Madrid: Cátedra.

- (2012): Audiovisual Translation: Dubbing, Londres y Nueva York: Routledge.

Díaz Cintas, Jorge (2007): «Traducción audiovisual y accesibilidad» en Jiménez Hurtado, C. (ed.): Traducción y accesibilidad. Subtitulación para sordos y audiodescripción para ciegos: nuevas modalidades de Traducción Audiovisual. Frankfurt: Peter Lang, 9-23.

Jiménez Hurtado, Catalina (2007a): «La Audiodescripción desde la representación del conocimiento general. Configuración semántica de una gramática local del texto audiodescrito", Linguistica Antverpiensia, 6:345-346, <https://lans-tts. uantwerpen.be/index.php/LANs-TTs/article/ viewFile/ı96/ı27> [consulta: I2-X-20I5].

- (2007b): «Una gramática local del guion audiodescrito. Desde la semántica a la pragmática de un nuevo tipo de traducción» en Jiménez Hurtado, C. (ed.): Traducción y accesibilidad. Subtitulación para sordos y audiodescripción para ciegos: nuevas modalidades de Traducción Audiovisual. Frankfurt: Peter Lang, 55-79.

Matamala, Anna (2005): «Live Audio Description in Catalonia», Translating Today, 4: 9-II.

Orero, Pilar (2007): «Audiosubtitling: A Possible Solution for Opera Accessibility in Catalonia», TradTerm, I3: I35-I49.

Ramos Caro, Marina (20I3): El impacto emocional de la Audiodescripción. Universidad de Murcia, Facultad de Letras. Tesis doctoral, <https:/digitum.um.es/ xmlui/handle/IO2OI/36475> [consulta: I3-VIII-2OI5]. 